\title{
Comparative Analysis on the Effects of Natural \& Artificial Indoors Lighting on the Learning and Interactive Process
}

\author{
MOSTAFA M. E. F. SHAMS, HOSAM ABD El- AZIZ AMR, \& RANIA RUSHDY MOUSSA
}

\author{
Architecture Department, Faculty of Engineering \\ The British University in Egypt (BUE) \\ El-Sherouk City, Cairo 11837 \\ EGYPT
}

\begin{abstract}
Schools and universities are the main spaces for learning, in which he building design can easily affect the learning and interactive process where indoor environment should be considered carefully when designing these learning spaces. One of the most important factors considered is lighting. The aim of this research is to investigate the effect of different types of indoor lighting on the learning and interactive process. In this research, The indoors lighting efficacy in two different types of educational places were tested in a quantitative way in addition to users survey for these places to test their satisfaction with the current indoor lighting quality which results that the users prefers natural lighting although it got negative feedback due to inconsistency. Finally, this research gives some recommendations for the usage of the indoors lighting to further enhance the learning and interactive process.
\end{abstract}

Key-Words: - Lighting Indoors; Natural lighting; Artificial lighting; learning and Interactive process; Human comfort.

Received: January 21, 2021. Revised: June 17, 2021. Accepted: June 30, 2021. Published: July 8, 2021.

\section{Introduction}

Energy consumption and reduction is the main scope of research in the past decade, many researchers tried to find alternative source of clean energy and others tried to minimize the energy consumptions [1,2,3\&4]. Educational buildings are one of the main types of building that consumes high energy monthly, not associated to the industry in a country. Many simulations and designing software's such as design-builders were used to estimate the amount of energy consumed in building as a tool to control and reduce the buildings energy consumptions [5]. In US educational buildings it costs up to 6 billion dollars a year. There is a huge association between the results of tests and the indoor ventilation rate, temperature and high contact surfaces hygiene. This shows a large association between the indoor environment and the satisfaction of with the studying environment. Previous studies and researches shows that the learning performance is reduced by $30 \%$ due to poor indoor environment [6]. The atmospheric components of the indoor environments consist of three aspects: ambient, design and social factors which all are associated with the indoor environmental quality [7].

\section{Lighting}

"Light is essential for humans. It is commonly known that light is an important factor in physical and psychological behaviours. Since the late 1990s, great quality lighting balanced the needs of humans, economic and environmental issues, and architectural design." Good lighting is an important contributor in good visual performance, special appearances, good health and yet it additionally decides spatial appearance, it accommodates wellbeing, and it adds to prosperity $[8,9]$.

\subsection{Luminous flux (luminous output):}

Energy produced by the light source cannot be fully considered as light energy. for instance, an incandescent lamp transforms a certain amount of consumed electric energy into radiant energy, out of this, the majority of this energy is considered as heat, and the rest (about 10\%) is considered as light to the human eye [10].

"Luminous flux is the total amount of light radiated or emitted by the source of light in all directions in one second." It is measured in lumens (lm) and represented by the Greek letter $(\Phi)[10]$. 


\subsection{Illuminance (Luminous level):}

"Luminous level or Illuminance is the ratio between the Luminous flux received by a surface to its surface. Its unit is the Lux (lx) and represented by the letter (E)."

Therefore, the formula that expresses Illuminance is: $\mathrm{E}=\frac{\Phi}{\mathrm{s}}\left(l x=l \mathrm{~m} / \mathrm{m}^{2}\right)$

"Therefore, according to this formula, the higher the Flux applied on a surface, the higher the illuminance will be, also for the same Flux; the illuminance will increase as the surface decreases." [10].

According to previous researches the recommended percentage of Lux in study places is shown in table 1 [10].

Table 1. Recommended lux in specific study areas [10]

\begin{tabular}{l|l|l}
\hline Area type & $\begin{array}{l}\text { Illuminance is } \\
\text { service (lux) }\end{array}$ & Quality Class \\
\cline { 1 - 1 } Workshop & 300 & \\
\cline { 1 - 1 } Libraries & & \multirow{2}{*}{ A-B } \\
\cline { 1 - 1 } Reading rooms & & \\
\cline { 1 - 1 } Classrooms & 500 & \\
\cline { 1 - 1 } Assembly halls & & \\
\cline { 1 - 1 } Laboratories & & \\
\cline { 1 - 1 } Art rooms & & \\
\cline { 1 - 1 } Sports halls & & \\
\hline
\end{tabular}

\section{$3 \quad$ Natural Lighting}

Daylight was the primary light source in buildings before the 1940s.

Sun light intensity, angles and effects have never changed, however architects with the passage of time started to increase their usage of natural lighting in their designs. This usage of sun light occurred for a variety of reasons such as:

1) Energy saving: how to use natural lighting to decrease the usage of artificial lighting, which reduce the power consumption and its cost.

2) As an architectural element: architects often use sun light and shadow to enhance their façade design.

3) Its psychological and physiological effects: Natural lighting is linked to high productivity, fewer errors or defects in products, lower eyestrain, lower fatigue and positive attitudes [11]. Moreover, lighting has a lot of physical and psychological benefits as described in table 2 [12].

\section{$4 \quad$ Artificial Lighting}

Ever since the 1940s, artificial lighting supplemented the natural lighting. In the short span of 20 years, artificial lighting transformed workshops to satisfy most if not all the needs of its users lighting requirements [11]. There are a lot of types of artificial lighting such as Incandescent lamps, High pressure mercury discharge lamps, High pressure sodium discharge lamps and Induction lamps. All these types have their advantages, disadvantages and methods of usage [10].

\section{$5 \quad$ Research Methods}

\begin{tabular}{c|c|c|c}
\hline \multicolumn{3}{c}{ Table 2.Natural light and human body[12] } \\
\hline \multicolumn{2}{c}{ Physically } & \multicolumn{2}{c}{ Psychologically } \\
\hline Improve & Decrease & Improve & Decrease \\
\hline Vitamin D & $\begin{array}{c}\text { Cancer } \\
\text { Possibility }\end{array}$ & Mood & Depression \\
\hline $\begin{array}{c}\text { Visual } \\
\text { System }\end{array}$ & $\begin{array}{c}\text { Abnormal } \\
\text { Bone } \\
\text { Formation }\end{array}$ & $\begin{array}{c}\text { Mental } \\
\text { Performance }\end{array}$ & Stress \\
\hline $\begin{array}{c}\text { Circadian } \\
\text { Rhythms }\end{array}$ & - & Alertness & Sadness \\
\hline $\begin{array}{c}\text { Sleep } \\
\text { Quality }\end{array}$ & - & Brain & $\begin{array}{c}\text { Violent } \\
\text { Behaviour }\end{array}$ \\
\hline
\end{tabular}

The research applied an environmental experiment for investigating the effects of indoors lighting on the learning and interactive process. Due to the nature of this research, it is correlational, which is the study of the relationship of two or more variables. The research components will be reached with a quantitative approach, which is the research method, that took place in two phases. Phase One: by measuring the light Illuminance in two different types of study rooms, knowing that the data were gathered in specific spots in the two rooms. Phase Two: the research applied a quantitative survey, where the users were asked about the two rooms and their specific opinion of the quality of lighting in both rooms.

\subsection{Study Area}

This research took place in two different types of study rooms inside building " $A$ " in the "British 
University in Egypt" (BUE) as shown in Fig 1 and Fig 2.

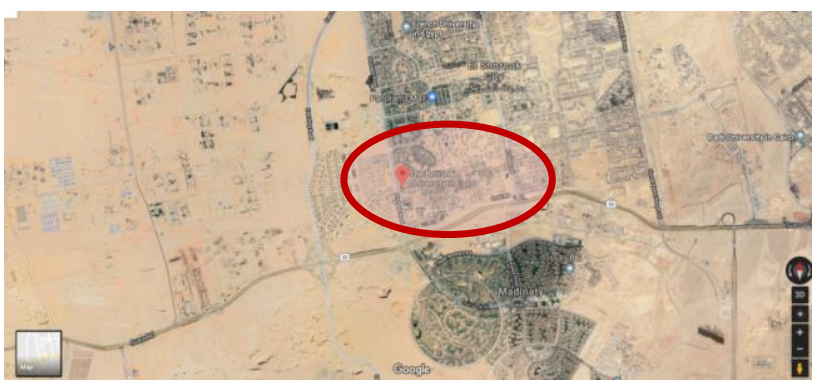

Figure 1. The Location of the British University in Egypt in Sherouk city

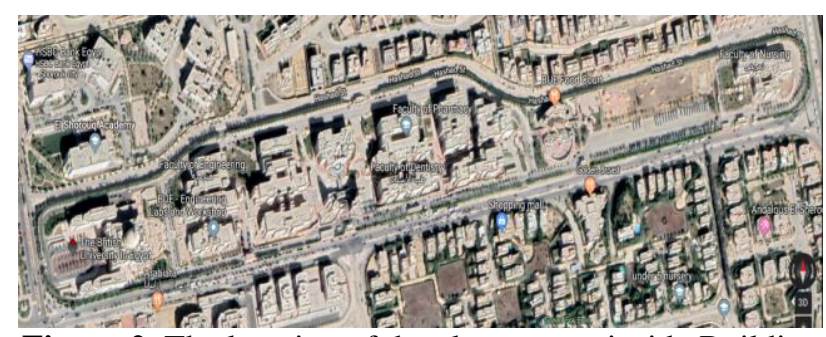

Figure 2. The location of the class rooms inside Building

A, The study area of this research

The first Room is called "CAD CAM Lab" which is located in the first floor of the building. It has a dimension of $17.5 \mathrm{~m} \times 8.5 \mathrm{~m}$. This Lab is intended for mostly computerized designing work for engineers. It has 18 sets of artificial lighting with each set having $4(60 \mathrm{~cm})$ florescent tubes reaching a total of 72 florescent tubes in total as shown in figure 3 .
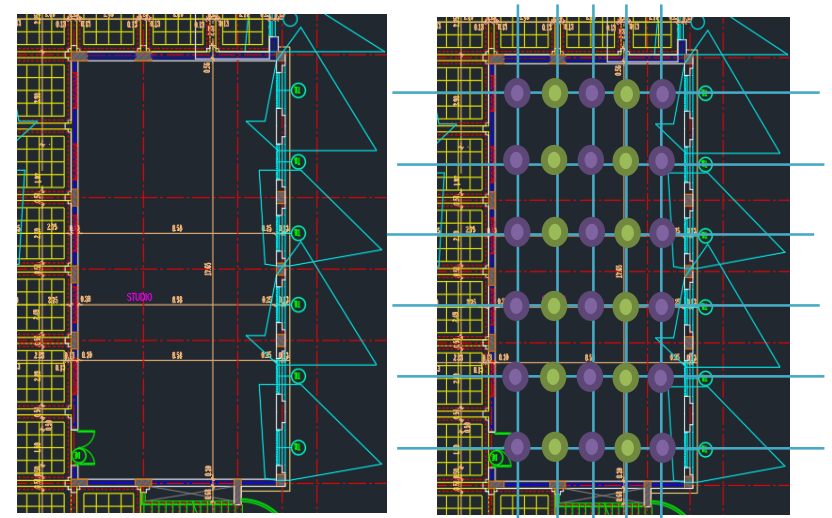

Directly Under an Artificial light source

- Un-Directly Under a light source

Figure 3. Light distribution inside the study area

The second Room is called "Room-311" located on the third floor. It has a dimension of $\quad 8.6 \mathrm{~m} \mathrm{x}$ $5.75 \mathrm{~m}$. This room is a normal class room with a white board and a data show projector. It has 10 sets of artificial lighting with each set having $4(60 \mathrm{~cm})$ florescent tubes reaching a total of 40 florescent tubes in total as shown in figure 4.

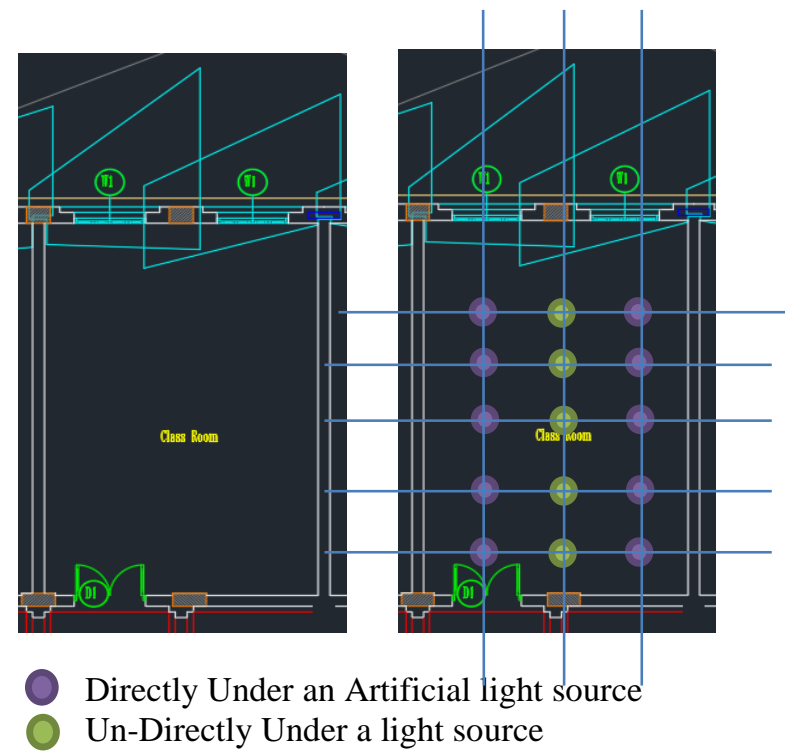

Figure 4. Lighting distribution inside class room-311

$$
\text { Plan }
$$

\subsection{Characteristics of Participants}

The participants were chosen according to their constant participation in the two classes along the semester. The research participants were given a questionnaire to measure their evaluation for the indoors lighting environment of the two rooms. A total of 73 participants were surveyed during April 2021. The participants were divided between the two rooms, 45 persons participated in the "CAD CAM Lab" and 28 persons participated in "Room311". The distribution of participants demographic and social characteristics, such as Gender, age and education level are presented in table 3 and 4 .

Table 3. Demographic and social characteristics of the research participants inside "CAD CAM Lab"

\begin{tabular}{llll}
\hline Gender & & Age & Education level \\
\hline Male & $57 \%$ & $17-22$ & $\begin{array}{l}\text { Engineering } \\
\text { students }\end{array}$ \\
Female & $43 \%$ & & \\
\hline
\end{tabular}

Table 4. Demographic and social characteristics of the research participants inside "Room-311

\begin{tabular}{lccl}
\hline Gender & & Age & Education level \\
\hline Male & $87 \%$ & $17-22$ & $\begin{array}{l}\text { Engineering } \\
\text { students }\end{array}$ \\
Female & $13 \%$ & & \\
\hline
\end{tabular}




\subsection{Data Collection Questionnaires}

In this research, questionnaires were chosen to be the data collection method from the students inside the chosen study areas. A short questionnaire consisting of 5 questions, as shown in the appendix, has been used in this research. These questions were used to measure the quality of indoors lighting according to each student in their classroom. Students were asked to evaluate the quality of the natural and artificial lighting in both rooms, as great is the highest satisfaction level, and poor is the lowest, with (below average, average and above average) in between.

\subsection{Equipment}

As the main equipment to measure the illuminance, a lux meter was used to measure the illuminance of artificial and natural lighting in both rooms as shown in Fig 5.

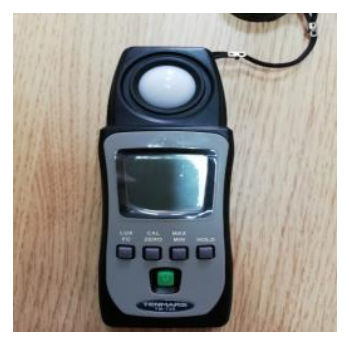

Figure 5. The lux meter used in the experiment

\subsection{Procedures}

This research were made in April 2021, it started by choosing the study area. After the study areas were chosen, taking into perspective being different in nature, as the "CAD CAM Lab" is mostly used for software designing, and being vastly larger than "Room-311". On the other side, "Room-311" is a normal class room with both a white board and a data show projector. After that, the questionnaire was distributed among the students using both rooms. Then a lux meter was used to measure the illuminance inside both rooms. (See the appendix). The illuminance was measured on disk height around $0.7-0.8 \mathrm{~m}$. Also, the illuminance was measured for the artificial and natural lighting in the "CAD CAM Lab", and the artificial lighting in "Room-311". Finally $82 \%$ of the total amount of students agreed that lighting affects the learning process.

\section{RESULTS}

This section will be divided into two Parts: 1 . the results for the "CAD CAM Lab",

2.The results for "Room-311". The results will be for both the questionnaire and the illuminance measurements.

\subsection{Results for "CAD CAM Lab"}

According to the site observation, as well as $84 \%$ of the students stated that the artificial lighting is the most commonly used type of lighting inside the computer lab. On the other hand, $73 \%$ of the total amount of students stated that the students prefer the natural lighting more than artificial lighting.

The percentage of satisfaction toward the amount of light in "CAD CAM Lab" is shown in figure 6, the evaluation of natural lighting made by students varied from one another. Most of the students answers leaned to the negative side, as $31 \%$ of the students said that the natural lighting was poor and $20 \%$ saying its below average. However, $35 \%$ of the students said it was average and the last $14 \%$ was divided equally between above average and Great.

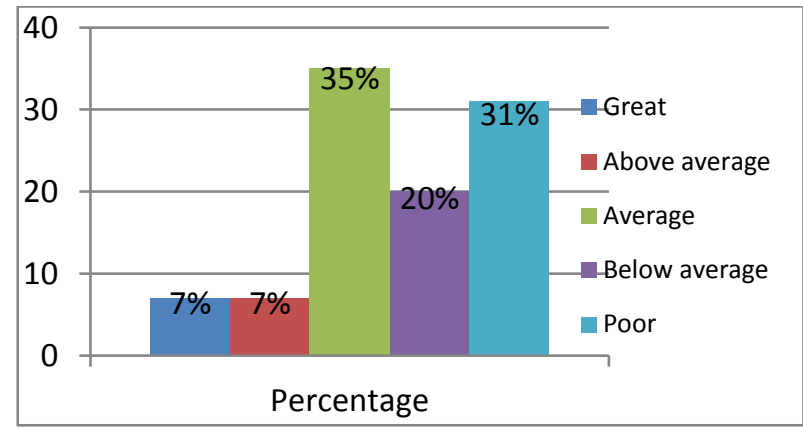

Figure 6. Satisfaction level with the Natural lighting in "CAD CAM Lab"

The illuminance level varied in intensity inside the "CAD CAM Lab". Fig 7 shows the illuminance highly increasing beside the window openings, and rapidly decreasing as you go deeper in the room. The mean value of illuminance in column 3 which is the nearest to the windows was $534 \mathrm{~lx}$, and the mean value of column 2 in the middle of the room was 223.7 lx, lastly the mean value of column 1 which is the furthest away from the windows was $141.3 \mathrm{~lx}$. 


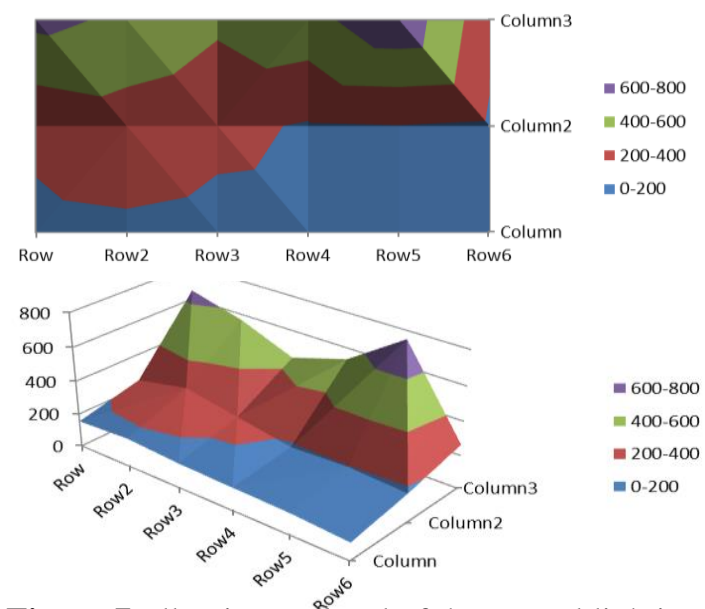

Figure 7. Illuminance level of the natural lighting in the "CAD CAM Lab"

On the other hand, Fig 8 shows the students mostly agreed that the artificial lighting was average or above average, with $40 \%$ saying average, 31\% saying above average and $9 \%$ saying it is great. However, $11 \%$ and $9 \%$ said the lighting was below average and poor respectively.

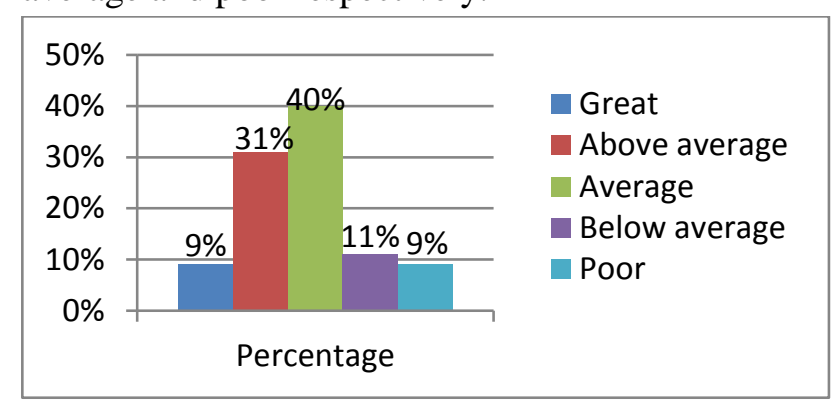

Figure 8. The level of student's satisfaction with the artificial lighting inside "CAD CAM Lab"

As for the Artificial lighting, Fig 9 shows that the illuminance inside the whole room stayed mostly average in intensity, measuring a mean value of 229.91x.

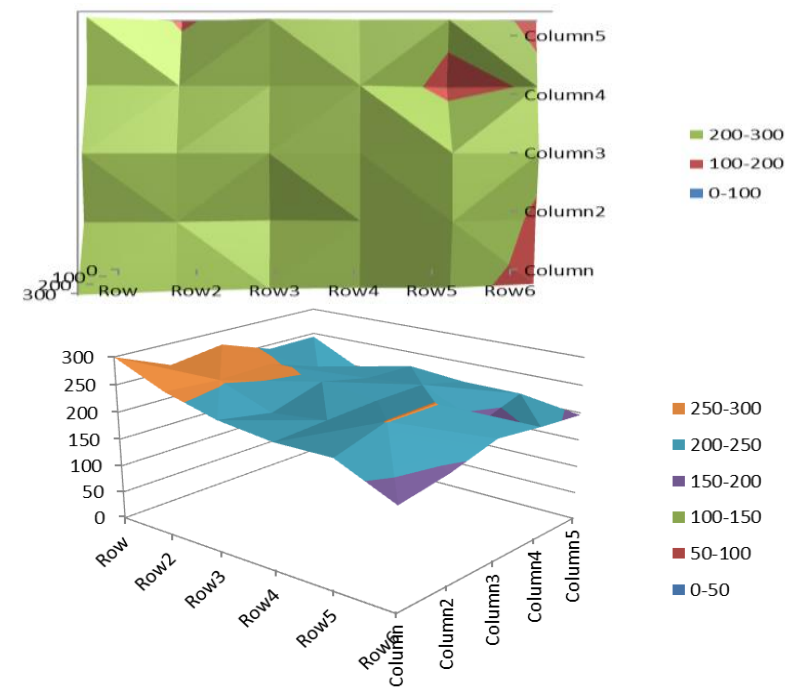

Figure 9. Illuminance level of the artificial lighting in the "CAD CAM Lab"

\subsection{Results of Class room-311}

According to the site observation, as well as $89 \%$ of the students said that the artificial lighting is the most commonly used type of lighting inside the Room. On the other hand, $61 \%$ of the total amount of students said that the Natural lighting is their preferred type of lighting.

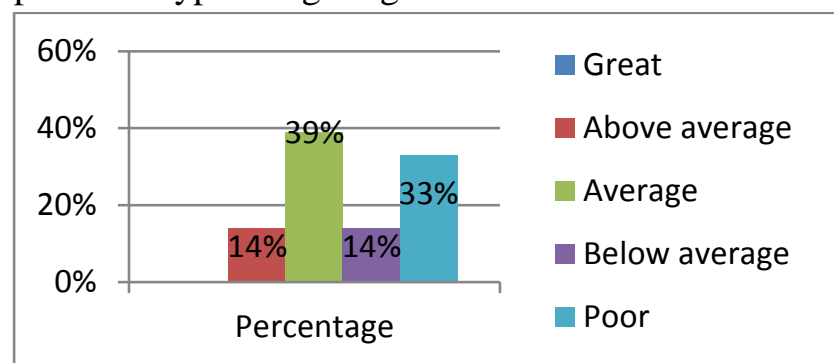

Figure 10. The level of student's satisfaction with the natural lighting inside "Class Room-311"

According to figure 10, almost all the students agreed that the natural lighting inside the room is not good and it need more natural lighting. Only $14 \%$ stated that their level of satisfaction is above average, $39 \%$ stated that it is average, while $14 \%$ stated that it is below average and 33\% agreeing that the natural lighting in the room is poor.

Moreover as shown in fig 11 , no students thought that the artificial lighting in the room was great. However, Most of the students feel that the artificial lighting is either above average or average with percentages of $29 \%$ and $53 \%$ respectively. This leaves $14 \%$ saying it is below average and only $4 \%$ saying its poor.

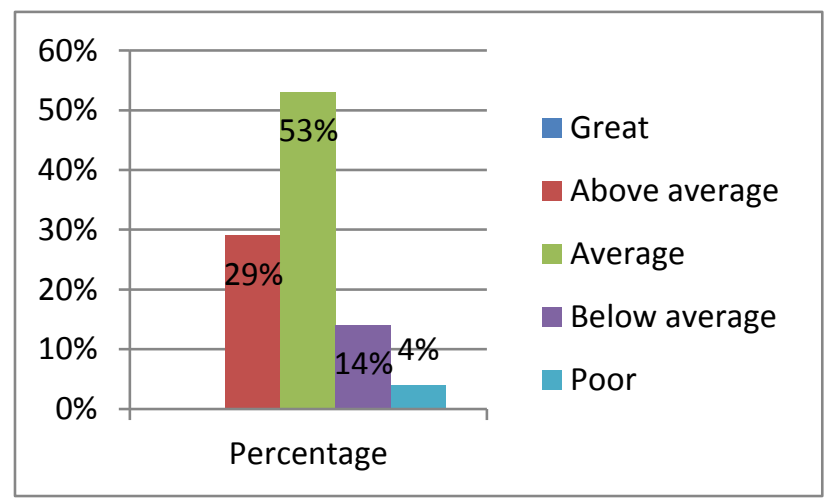

Figure 11. The level of student's satisfaction with the artificial lighting inside "Class Room-311"

Similar to the "CAD CAM Lab", the Artificial lighting illuminance in "Class Room-311" is mostly consistent along the whole room, measuring 
between 200-300 lx, with small areas near the edges of the room measuring higher. The room has a mean value of $284.8 \mathrm{~lx}$ as shown in figure 12 .

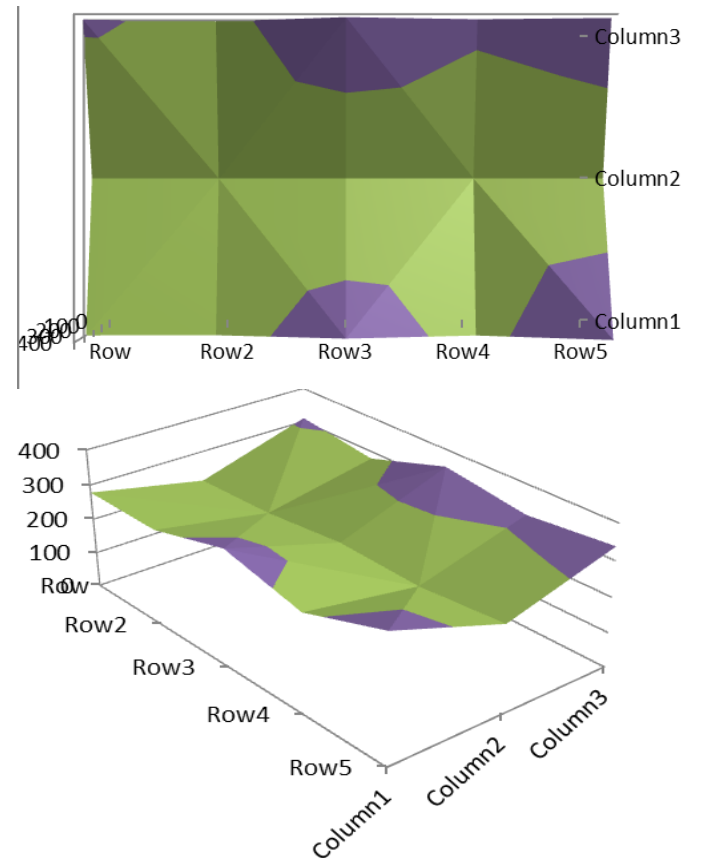

- $300-400$

$=200-300$

- $100-200$

= 0-100

= $300-400$

$=200-300$

=100-200

= 0-100

Figure 12. Illuminance level of the artificial lighting in "Class Room-311"

\section{Discussion}

After measuring the illuminance of both rooms for artificial and natural lightings, the huge agreement among the students that their preferred type of lighting is the natural lighting. This conclusion is logical knowing all physical and psychological benefits of the natural lighting [12]. However, in both rooms the evaluation of the natural lighting collected from students leaned towards the negative side. This result is logical because after the measuring of the natural lighting luminance is not consistent in the rooms, because there is no means for the natural lighting to fully illuminate the far ends of the rooms. On the other side, the artificial lighting wasn't considered by most students as their preferred type of lighting, it received a more positive evaluation from the same students. This is happening because the artificial lighting is mostly consistent in the rooms. The illuminance in the "CAD CAM Lab" and in "Room-311" had a mean value of 229.91x and $284.81 \mathrm{~lx}$, which is still less than the 3001x recommended by both [10] and [13] in class rooms. Still it's most commonly used because it's more consistent and controllable than natural lighting, in addition that in both rooms the needed illuminance is less than normal because of the presence of data shows and computers [14].

\section{Conclusion}

An important part of the designing process is the Indoor environment, as the indoors lighting being a huge contributor in it. The research concludes that as long as the artificial lighting is most commonly used, students in the "CAD CAM Lab" and "Room311" preferred natural lighting. However, natural lighting got more negative feedback inside the room from the same students; this negative feedback was due to the inconsistency of natural lighting inside the rooms. On the other hand, artificial lighting got a more positive feedback, because its illuminance was more consistent in both rooms.

This leads to a conclusion that the consistency of lighting is very important to users and designers should improve the consistence of natural lighting inside studying areas while designing building opening. Further studies should be done in this topic to improve the effect of natural lighting in the quality of studying areas.

\section{References:}

[1] Moussa, R.R. (2018). The role of energy-scape elements in creating sustainable economic project in Egyptian parks. Ain Shams Engineering Journal, 9(4); 3045-3053.

[2] Moussa, R.R. (2019). The Reasons For Not Implementing Green Pyramid Rating System In Egyptian Buildings. Ain Shams Engineering Journal, 10(4); 917-927.

[3] Moussa, R.R., Mahmoud, A.H., and Hatem, T.M. (2020). A digital tool for integrating renewable energy devices within landscape elements: Energy-scape online application. Journal of Cleaner Production, 254; 1-13.

[4] Moussa, R.R. and Dewidar, K.M. (2020). Energy-scape web-based application is an effective tool to overcome the basic knowledge of architects toward renewable energy properties. International Journal of Emerging Technologies in Learning (iJET), 15(10); 4254. Retrieved from: https://doi.org/10.3991/ijet.v15i10.13669

[5] Moussa, R.R. and Moawad, D.R.M. (2020). Investigating the Efficiency of Building Energy Simulation Software's on Architectural Design Process (April 9-12, 2020). 9th International Conference on Software and Information Engineering (ICSIE 2020). Cairo_Egypt. Page 37-40. ACM International Conference Proceeding Series, 2020, pp. 37-40. Retrieved from:

https://doi.org/10.1145/3436829.3436860 
[6] Buratti, C., Belloni, E., Merli, F. and Ricciardi, P. (2018). A new index combining thermal, acoustic, and visual comfort of moderate environments in temperate climates. Building and Environment, 139, pp.27-37.

[7] Yildirim, K., Akalin-Baskaya, A. and Hidayetoglu, M. (2007). Effects of indoor color on mood and cognitive performance. Building and Environment, 42(9), pp.3233-3240.

[8] Bellia, L., Bisegna, F. and Spada, G. (2011). Lighting in indoor environments: Visual and non-visual effects of light sources with different spectral power distributions. Building and Environment, 46(10), pp.1984-1992.

[9] Ahmed, M.O., Madkor, A.K., Makeen, P., Betelmal, S.E.I., Hassan, M.M., Abdelsamee, M.M., Ayman, A., El-Adly, M.H., Nessim, A. Abdullatif, S.O. (2021) Optimizing the Artificial Lighting in a Smart and Green Glass Building-integrated Semi-Transparent Photovoltaics: A Multifaceted Case Study in Egypt. WSEAS Transactions on Environment and Development, 17: 118-127

[10] INDALUX. (2002). LIGHTING ENGINEERING 2002. Available at: https://issuu.com/lightonline/docs/lightinghandbook-indal-guide (Accessed: 18 April 2019).

[11] Edwards, L. and Torcellini, P. (2002). A literature review of the effects of natural light on building occupants. Golden, CO: National Renewable Energy Laboratory.

[12] Shishegar, N. and Boubekri, M. (2016). Natural Light and Productivity: Analyzing the Impacts of Daylighting on Students' and Workers' Health and Alertness. International Journal of Advances in Chemical Engineering and Biological Sciences, 3(1).

[13] ZUMTOBEL. (2018). The Lighting Handbook. Available at: https://www.zumtobel.com/PDB/Ressource/tea ser/en/Lichthandbuch.pdf (Accessed: 29 April 2019).

[14] Drabek, P. and Zalesak, M. (2018). Comparison of Lighting Simulation Outcomes for Electric Lights with Real Reference. WSEAS TRANSACTIONS on ENVIRONMENT and DEVELOPMENT, 14: 584-589.

\section{Contribution of individual authors to the creation of a scientific article (ghostwriting policy)}

Mostafa shams has executed the empirical work Hosam Abd el-Aziz and Rania Moussa has organized, supervised the execution of the manuscript. 